\title{
Some coincidence and common fixed point theorems for ordered Prešić-Reich type contractions
}

Satish Shukla', Slobodan Radojević 2 $^{*}$, Zorica A Veljković ${ }^{3}$ and Stojan Radenović ${ }^{2}$

"Correspondence:

sradojevic@mas.bg.ac.rs

${ }^{2}$ Department of Mathematics,

Faculty of Mechanical Engineering,

University of Belgrade, Kraljice

Marije 16, Belgrade, 11120, Serbia

Full list of author information is

available at the end of the article

\begin{abstract}
The purpose of this paper is to prove some coincidence and common fixed point theorems for ordered Prešić-Reich type contractions in ordered metric spaces. Results of this paper generalize and extend several known results from metric spaces into product spaces when the underlying space is an ordered metric space. An example illustrates the case when new results can be applied while old ones cannot.
\end{abstract}

Keywords: Prešić type mapping; coincidence point; common fixed point; ordered space

\section{Introduction and preliminaries}

The well-known Banach contraction mapping principle states that if $(X, d)$ is a complete metric space and $f: X \rightarrow X$ is a self-mapping such that

$$
d(f x, f y) \leq \lambda d(x, y)
$$

for all $x, y \in X$, where $0 \leq \lambda<1$, then there exists a unique $x \in X$ such that $f x=x$. This point $x$ is called the fixed point of the mapping $f$. On the other hand, for mappings $f: X \rightarrow X$, Kannan [1] introduced the contractive condition

$$
d(f x, f y) \leq \lambda[d(x, f x)+d(y, f y)]
$$

for all $x, y \in X$, where $\lambda \in\left[0, \frac{1}{2}\right)$ is a constant and proved a fixed point theorem using (2) instead of (1). Conditions (1) and (2) are independent, as it was shown by two examples in [2].

Reich [3], for mappings $f: X \rightarrow X$, generalized Banach and Kannan fixed point theorems using the contractive condition

$$
d(f x, f y) \leq \alpha d(x, y)+\beta d(x, f x)+\gamma d(y, f y)
$$

for all $x, y \in X$, where $\alpha, \beta, \gamma$ are nonnegative constants with $\alpha+\beta+\gamma<1$. An example in [3] shows that condition (3) is a proper generalization of (1) and (2).

In 1965, Prešić $[4,5]$ extended the Banach contraction mapping principle to mappings defined on product spaces and proved the following theorem.

@2013 Shukla et al.; licensee Springer. This is an Open Access article distributed under the terms of the Creative Commons Attribution License (http://creativecommons.org/licenses/by/2.0), which permits unrestricted use, distribution, and reproduction in any medium, provided the original work is properly cited. 
Theorem 1.1 Let $(X, d)$ be a complete metric space, $k$ be a positive integer and $f: X^{k} \rightarrow X$ be a mapping satisfying the following contractive type condition:

$$
d\left(f\left(x_{1}, x_{2}, \ldots, x_{k}\right), f\left(x_{2}, x_{3}, \ldots, x_{k+1}\right)\right) \leq \sum_{i=1}^{k} q_{i} d\left(x_{i}, x_{i+1}\right)
$$

for every $x_{1}, x_{2}, \ldots, x_{k+1} \in X$, where $q_{1}, q_{2}, \ldots, q_{k}$ are nonnegative constants such that $q_{1}+q_{2}+$ $\cdots+q_{k}<1$. Then there exists a unique point $x \in X$ such that $f(x, x, \ldots, x)=x$. Moreover, if $x_{1}, x_{2}, \ldots, x_{k}$ are arbitrary points in $X$ and for $n \in \mathbb{N}, x_{n+k}=f\left(x_{n}, x_{n+1}, \ldots, x_{n+k-1}\right)$, then the sequence $\left\{x_{n}\right\}$ is convergent and $\lim x_{n}=f\left(\lim x_{n}, \lim x_{n}, \ldots, \lim x_{n}\right)$.

Note that condition (4) in the case $k=1$ reduces to the well-known Banach contraction mapping principle. So, Theorem 1.1 is a generalization of the Banach fixed point theorem. Some generalizations and applications of the Prešić theorem can be seen in [4-19].

The existence of a fixed point in partially ordered sets was investigated by Ran and Reurings [20] and then by Nieto and Lopez [21, 22]. Fixed point results in ordered metric spaces were obtained by several authors (see, e.g., $[6,18,23-32])$. The following version of the fixed point theorem was proved, among others, in these papers.

Theorem 1.2 (see [22] and references therein) Let $(X, \preceq)$ be a partially ordered set, and let $d$ be a metric on $X$ such that $(X, d)$ is a complete metric space. Let $f: X \rightarrow X$ be a nondecreasing map with respect to $\preceq$. Suppose that the following conditions hold:

(i) there exists $k \in(0,1)$ such that $d(f x, f y) \leq k d(x, y)$ for all $x, y \in X$ with $y \leq x$;

(ii) there exists $x_{0} \in X$ such that $x_{0} \preceq f x_{0}$;

(iii) $f$ is continuous.

Then $f$ has a fixed point $x^{*} \in X$.

Păcurar [10] introduced the Prešić-Kannan type contraction and proved some common fixed point theorems for such contractions. Very recently, in [18] (see also [33]) authors introduced the ordered Prešić type contraction and generalized the result of Prešić and proved some fixed point theorems for such mappings. In this paper, we introduce the ordered Prešić-Reich type contraction and prove some common fixed point theorems for such type of mappings in ordered metric spaces. Our results generalize and extend the results of Prešić [4, 5], Pǎcurar [10], Malhotra et al. [18], Luong and Thuan [33], Nieto and López [21] and several known results of metric spaces. An example, which illustrates the case when new results can be applied while old ones cannot, is included.

The following definitions will be needed in the sequel.

Definition 1.3 Let $X$ be a nonempty set, $k$ be a positive integer and $f: X^{k} \rightarrow X$ be a mapping. If $f(x, x, \ldots, x)=x$, then $x \in X$ is called a fixed point of $f$.

Definition 1.4 (see [13]) Let $X$ be a nonempty set, $k$ be a positive integer, $f: X^{k} \rightarrow X$ and $g: X \rightarrow X$ be mappings.

(a) An element $x \in X$ is said to be a coincidence point of $f$ and $g$ if $g x=f(x, \ldots, x)$.

(b) If $w=g x=f(x, \ldots, x)$, then $w$ is called a point of coincidence of $f$ and $g$.

(c) If $x=g x=f(x, \ldots, x)$, then $x$ is called a common fixed point of $f$ and $g$. 
(d) Mappings $f$ and $g$ are said to be commuting if $g(f(x, \ldots, x))=f(g x, \ldots, g x)$ for all $x \in X$.

(e) Mappings $f$ and $g$ are said to be weakly compatible if they commute at their coincidence points.

Remark that the above definition in the case $k=1$ reduces to the usual definitions of commuting and weakly compatible mappings in the sense of [34] (for details, see the Introduction from [34]).

Definition 1.5 (see [18]) Let a nonempty set $X$ be equipped with a partial order ' $\preceq$ ' such that $(X, d)$ is a metric space, then $(X, \preceq, d)$ is called an ordered metric space. A sequence $\left\{x_{n}\right\}$ in $X$ is said to be nondecreasing with respect to ' be a positive integer and $f: X^{k} \rightarrow X$ be a mapping, then $f$ is said to be nondecreasing with respect to ' $\preceq$ ' if for any finite nondecreasing sequence $\left\{x_{n}\right\}_{n=1}^{k+1}$ we have $f\left(x_{1}, x_{2}, \ldots, x_{k}\right) \preceq$ $f\left(x_{2}, x_{3}, \ldots, x_{k+1}\right)$. Let $g: X \rightarrow X$ be a mapping. $f$ is said to be $g$-nondecreasing with respect to ' $\preceq$ ' if for any finite nondecreasing sequence $\left\{g x_{n}\right\}_{n=1}^{k+1}$ we have $f\left(x_{1}, x_{2}, \ldots, x_{k}\right) \preceq$ $f\left(x_{2}, x_{3}, \ldots, x_{k+1}\right)$.

Remark 1.6 For $k=1$, the above definitions reduce to usual definitions of fixed point and nondecreasing mapping in a metric space.

Definition 1.7 Let $X$ be a nonempty set equipped with partial order ' $\preceq$,' and let $g: X \rightarrow X$ be a mapping. A nonempty subset $\mathcal{A}$ of $X$ is said to be well ordered if every two elements of $\mathcal{A}$ are comparable. Elements $a, b \in \mathcal{A}$ are called $g$-comparable if $g a$ and $g b$ are comparable. $\mathcal{A}$ is called $g$-well ordered if for all $a, b \in \mathcal{A}, a$ and $b$ are $g$-comparable, i.e., $g a$ and $g b$ are comparable.

Example 1.8 Let $X=\{0,1,2,3\}$, ' $\preceq$ ' be a partial order relation on $X$ defined by $\preceq=$ $\{(0,0),(1,1),(2,2),(3,3),(1,2),(2,3),(1,3)\}$. Let $\mathcal{A}=\{0,1,3\}$ and $g: X \rightarrow X$ be defined by $g 0=1, g 1=2, g 2=3, g 3=3$. Then it is clear that $\mathcal{A}$ is not well ordered but it is $g$-well ordered.

Let $(X, \preceq, d)$ be an ordered metric space. Let $k$ be a positive integer and $f: X^{k} \rightarrow X$ be a mapping. $f$ is said to be an ordered Prešić type contraction if

$$
d\left(f\left(x_{1}, x_{2}, \ldots, x_{k}\right), f\left(x_{2}, x_{3}, \ldots, x_{k+1}\right)\right) \leq \sum_{i=1}^{k} \alpha_{i} d\left(x_{i}, x_{i+1}\right)
$$

for all $x_{1}, x_{2}, \ldots, x_{k+1} \in X$ with $x_{1} \preceq x_{2} \preceq \cdots \preceq x_{k+1}$, where $\alpha_{i}$ are nonnegative constants such that $\sum_{i=1}^{k} \alpha_{i}<1$. If (5) is satisfied for all $x_{1}, x_{2}, \ldots, x_{k+1} \in X$, then $f$ is called a Prešić type contraction.

$f$ is said to be an ordered Prešić-Kannan type contraction (see [10] for details) if $f$ satisfies following condition:

$$
d\left(f\left(x_{1}, x_{2}, \ldots, x_{k}\right), f\left(x_{2}, x_{3}, \ldots, x_{k+1}\right)\right) \leq \beta \sum_{i=1}^{k+1} d\left(x_{i}, f\left(x_{i}, x_{i}, \ldots, x_{i}\right)\right)
$$


for all $x_{1}, x_{2}, \ldots, x_{k+1} \in X$ with $x_{1} \preceq x_{2} \preceq \cdots \preceq x_{k+1}$, where $0 \leq \beta k(k+1)<1$. If (6) is satisfied for all $x_{1}, x_{2}, \ldots, x_{k+1} \in X$, then $f$ is called a Prešić-Kannan type contraction.

$f$ is said to be an ordered Prešić-Reich type contraction (see also [16]) if $f$ satisfies the following condition:

$$
\begin{aligned}
d\left(f\left(x_{1}, x_{2}, \ldots, x_{k}\right), f\left(x_{2}, x_{3}, \ldots, x_{k+1}\right)\right) \leq & \sum_{i=1}^{k} \alpha_{i} d\left(x_{i}, x_{i+1}\right) \\
& +\sum_{i=1}^{k+1} \beta_{i} d\left(x_{i}, f\left(x_{i}, x_{i}, \ldots, x_{i}\right)\right)
\end{aligned}
$$

for all $x_{1}, x_{2}, \ldots, x_{k+1} \in X$ with $x_{1} \preceq x_{2} \preceq \cdots \preceq x_{k+1}$, where $\alpha_{i}, \beta_{i}$ are nonnegative constants such that $\sum_{i=1}^{k} \alpha_{i}+k \sum_{i=1}^{k+1} \beta_{i}<1$. If (7) is satisfied for all $x_{1}, x_{2}, \ldots, x_{k+1} \in X$, then $f$ is called a Prešić-Reich type contraction.

Note that the Prešić-Reich type contraction is a generalization of Prešić type and PrešićKannan type contractions. Indeed, for $\beta_{i}=0,1 \leq i \leq k+1$, a Prešić-Reich type contraction reduces into a Prešić type contraction and for $\alpha_{i}=0,1 \leq i \leq k$, and $\beta_{i}=\beta, 1 \leq i \leq k+1$, a Prešić-Reich type contraction reduces into a Prešić-Kannan type contraction. Also, for $k=1$, a Prešić-Reich type contraction reduces into a Reich contraction, so it generalizes the Banach and Kannan contractions.

Now we can state our main results.

\section{Main results}

Theorem 2.1 Let $(X, \preceq, d)$ be an ordered complete metric space. Let $k$ be a positive integer, $f: X^{k} \rightarrow X$ and $g: X \rightarrow X$ be two mappings such that $f\left(X^{k}\right) \subset g(X), g(X)$ is a closed subset of $X$ and

$$
\begin{aligned}
d\left(f\left(x_{1}, x_{2}, \ldots, x_{k}\right), f\left(x_{2}, x_{3}, \ldots, x_{k+1}\right)\right) \leq & \sum_{i=1}^{k} \alpha_{i} d\left(g x_{i}, g x_{i+1}\right) \\
& +\sum_{i=1}^{k+1} \beta_{i} d\left(g x_{i}, f\left(x_{i}, x_{i}, \ldots, x_{i}\right)\right)
\end{aligned}
$$

for all $x_{1}, x_{2}, \ldots, x_{k+1} \in X$ with $g x_{1} \preceq g x_{2} \preceq \cdots \preceq g x_{k+1}$, where $\alpha_{i}, \beta_{i}$ are nonnegative constants such that

$$
\sum_{i=1}^{k} \alpha_{i}+k \sum_{i=1}^{k+1} \beta_{i}<1 .
$$

Suppose that the following conditions hold:

(I) there exists $x_{0} \in X$ such that $g x_{0} \preceq f\left(x_{0}, x_{0}, \ldots, x_{0}\right)$;

(II) $f$ is $g$-nondecreasing;

(III) if a nondecreasing sequence $\left\{g x_{n}\right\}$ converges to gu $\in X$, then $g x_{n} \preceq$ gu for all $n \in \mathbb{N}$ and $g u \preceq g g u$.

Then $f$ and $g$ have a point of coincidence. If, in addition, $f$ and $g$ are weakly compatible, then $f$ and $g$ have a common fixed point $v \in X$. Moreover, the set of common fixed points of $f$ and $g$ is $g$-well ordered if and only if $f$ and $g$ have a unique common fixed point. 
Proof Starting with given $x_{0} \in X$, we define a sequence $\left\{y_{n}\right\}$ as follows: let $y_{0}=g x_{0}$, $y_{1}=f\left(x_{0}, x_{0}, \ldots, x_{0}\right)$. As $f\left(X^{k}\right) \subset g(X)$, there exists $x_{1} \in X$ such that $f\left(x_{0}, x_{0}, \ldots, x_{0}\right)=g x_{1}$. Therefore $y_{1}=g x_{1}=f\left(x_{0}, x_{0}, \ldots, x_{0}\right)$ as $g x_{0} \preceq f\left(x_{0}, x_{0}, \ldots, x_{0}\right)$, we have $g x_{0} \preceq g x_{1}$, that is, $y_{0} \preceq y_{1}$. Again, as $f$ is $g$-nondecreasing and $g x_{0} \preceq g x_{1}$, we have $f\left(x_{0}, x_{0}, \ldots, x_{0}\right) \preceq$ $f\left(x_{0}, \ldots, x_{0}, x_{1}\right) \preceq f\left(x_{0}, \ldots, x_{0}, x_{1}, x_{1}\right) \preceq \cdots \preceq f\left(x_{1}, x_{1}, \ldots, x_{1}\right)$. Choose $x_{2} \in X$ such that $y_{2}=$ $g x_{2}=f\left(x_{1}, x_{1}, \ldots, x_{1}\right)$ (which is possible since $\left.f\left(X^{k}\right) \subset g(X)\right)$. So, $g x_{0} \preceq g x_{1} \preceq g x_{2}$, that is, $y_{0} \preceq y_{1} \preceq y_{2}$. Continuing this process, we obtain

$$
g x_{0} \preceq g x_{1} \preceq \cdots \preceq g x_{n} \preceq g x_{n+1} \preceq \cdots,
$$

that is,

$$
y_{0} \preceq y_{1} \preceq y_{2} \preceq \cdots \preceq y_{n} \preceq y_{n+1} \preceq \cdots
$$

and $y_{n}=g x_{n}=f\left(x_{n-1}, x_{n-1}, \ldots, x_{n-1}\right)$ for $n=1,2, \ldots$ Thus, $\left\{y_{n}\right\}=\left\{g x_{n}\right\}$ is nondecreasing with respect to ' $\preceq$ ', that is, $\left\{x_{n}\right\}$ is $g$-nondecreasing with respect to ' $\preceq$.' We shall show that $\left\{y_{n}\right\}=\left\{g x_{n}\right\}$ is a Cauchy sequence in $g(X)$. If $y_{n}=y_{n+1}$ for any $n$, then

$$
\begin{aligned}
d\left(y_{n+1}, y_{n+2}\right)= & d\left(f\left(x_{n}, \ldots, x_{n}\right), f\left(x_{n+1}, \ldots, x_{n+1}\right)\right) \\
\leq & d\left(f\left(x_{n}, \ldots, x_{n}\right), f\left(x_{n}, \ldots, x_{n}, x_{n+1}\right)\right) \\
& +d\left(f\left(x_{n}, \ldots, x_{n}, x_{n+1}\right), f\left(x_{n}, \ldots, x_{n}, x_{n+1}, x_{n+1}\right)\right)+\cdots \\
& +d\left(f\left(x_{n}, x_{n+1}, \ldots, x_{n+1}\right), f\left(x_{n+1}, \ldots, x_{n+1}\right)\right) .
\end{aligned}
$$

As $g x_{n} \preceq g x_{n+1}$, using (8), the above inequality implies that

$$
\begin{aligned}
d\left(y_{n+1}, y_{n+2}\right) \leq & \alpha_{k} d\left(g x_{n}, g x_{n+1}\right)+\beta_{1} d\left(g x_{n}, f\left(x_{n}, \ldots, x_{n}\right)\right)+\cdots \\
& +\beta_{k} d\left(g x_{n}, f\left(x_{n}, \ldots, x_{n}\right)\right) \\
& +\beta_{k+1} d\left(g x_{n+1}, f\left(x_{n+1}, \ldots, x_{n+1}\right)\right) \\
& +\alpha_{k-1} d\left(g x_{n}, g x_{n+1}\right)+\beta_{1} d\left(g x_{n}, f\left(x_{n}, \ldots, x_{n}\right)\right)+\cdots \\
& +\beta_{k-1} d\left(g x_{n}, f\left(x_{n}, \ldots, x_{n}\right)\right) \\
& +\beta_{k} d\left(g x_{n+1}, f\left(x_{n+1}, \ldots, x_{n+1}\right)\right) \\
& +\beta_{k+1} d\left(g x_{n+1}, f\left(x_{n+1}, \ldots, x_{n+1}\right)\right)+\ldots \\
& +\alpha_{1} d\left(g x_{n}, g x_{n+1}\right)+\beta_{1} d\left(g x_{n}, f\left(x_{n}, \ldots, x_{n}\right)\right) \\
& +\beta_{2} d\left(g x_{n+1}, f\left(x_{n+1}, \ldots, x_{n+1}\right)\right)+\ldots \\
& +\beta_{k+1} d\left(g x_{n+1}, f\left(x_{n+1}, \ldots, x_{n+1}\right)\right)
\end{aligned}
$$

that is,

$$
\begin{aligned}
d\left(y_{n+1}, y_{n+2}\right) \leq & {\left[\sum_{i=1}^{k} \alpha_{i}\right] d\left(y_{n}, y_{n+1}\right)+\beta_{1} d\left(y_{n}, y_{n+1}\right)+\cdots+\beta_{k} d\left(y_{n}, y_{n+1}\right) } \\
& +\beta_{k+1} d\left(y_{n+1}, y_{n+2}\right)+\beta_{1} d\left(y_{n}, y_{n+1}\right)+\cdots+\beta_{k-1} d\left(y_{n}, y_{n+1}\right)
\end{aligned}
$$




$$
\begin{aligned}
& +\beta_{k} d\left(y_{n+1}, y_{n+2}\right)+\beta_{k+1} d\left(y_{n+1}, y_{n+2}\right)+\cdots+\beta_{1} d\left(y_{n}, y_{n+1}\right) \\
& +\beta_{2} d\left(y_{n+1}, y_{n+2}\right)+\cdots+\beta_{k+1} d\left(y_{n+1}, y_{n+2}\right) \\
\leq & {\left[k \beta_{k+1}+(k-1) \beta_{k}+\cdots+\beta_{2}\right] d\left(y_{n+1}, y_{n+2}\right) }
\end{aligned}
$$

since $y_{n}=y_{n+1}$. In view of (9), we have $k \beta_{k+1}+(k-1) \beta_{k}+\cdots+\beta_{2}=\sum_{i=2}^{k+1}(i-1) \beta_{i} \leq$ $k \sum_{i=2}^{k+1} \beta_{i}<1$, therefore it follows from the above inequality that $d\left(y_{n+1}, y_{n+2}\right)=0$, that is, $y_{n+1}=y_{n+2}$. Similarly, it can be shown that

$$
y_{n}=y_{n+1}=y_{n+2}=y_{n+3}=\cdots \text {. }
$$

Therefore $\left\{y_{n}\right\}$ is a Cauchy sequence. If $y_{n} \neq y_{n+1}$ for all $n$, then for any $n \geq 0$, we have

$$
\begin{aligned}
d\left(y_{n}, y_{n+1}\right)= & d\left(g x_{n}, g x_{n+1}\right) \\
= & d\left(f\left(x_{n-1}, \ldots, x_{n-1}\right), f\left(x_{n}, \ldots, x_{n}\right)\right) \\
\leq & d\left(f\left(x_{n-1}, \ldots, x_{n-1}\right), f\left(x_{n-1}, \ldots, x_{n-1}, x_{n}\right)\right) \\
& +d\left(f\left(x_{n-1}, \ldots, x_{n-1}, x_{n}\right), f\left(x_{n-1}, \ldots, x_{n-1}, x_{n}, x_{n}\right)\right)+\ldots \\
& +d\left(f\left(x_{n-1}, x_{n}, \ldots, x_{n}\right), f\left(x_{n}, \ldots, x_{n}\right)\right) .
\end{aligned}
$$

As $\left\{x_{n}\right\}$ is $g$-nondecreasing, using (8), the above inequality implies that

$$
\begin{aligned}
d\left(y_{n}, y_{n+1}\right) \leq & \alpha_{k} d\left(g x_{n-1}, g x_{n}\right)+\beta_{1} d\left(g x_{n-1}, f\left(x_{n-1}, \ldots, x_{n-1}\right)\right)+\cdots \\
& +\beta_{k} d\left(g x_{n-1}, f\left(x_{n-1}, \ldots, x_{n-1}\right)\right) \\
& +\beta_{k+1} d\left(g x_{n}, f\left(x_{n}, \ldots, x_{n}\right)\right) \\
& +\alpha_{k-1} d\left(g x_{n-1}, g x_{n}\right)+\beta_{1} d\left(g x_{n-1}, f\left(x_{n-1}, \ldots, x_{n-1}\right)\right)+\cdots \\
& +\beta_{k-1} d\left(g x_{n-1}, f\left(x_{n-1}, \ldots, x_{n-1}\right)\right) \\
& +\beta_{k} d\left(g x_{n}, f\left(x_{n}, \ldots, x_{n}\right)\right) \\
& +\beta_{k+1} d\left(g x_{n}, f\left(x_{n}, \ldots, x_{n}\right)\right)+\cdots \\
& +\alpha_{1} d\left(g x_{n-1}, g x_{n}\right)+\beta_{1} d\left(g x_{n-1}, f\left(x_{n-1}, \ldots, x_{n-1}\right)\right) \\
& +\beta_{2} d\left(g x_{n}, f\left(x_{n}, \ldots, x_{n}\right)\right)+\ldots \\
& +\beta_{k+1} d\left(g x_{n}, f\left(x_{n}, \ldots, x_{n}\right)\right)
\end{aligned}
$$

that is,

$$
\begin{aligned}
d\left(y_{n}, y_{n+1}\right) \leq & {\left[\sum_{i=1}^{k} \alpha_{i}\right] d\left(y_{n-1}, y_{n}\right) } \\
& +\beta_{1} d\left(y_{n-1}, y_{n}\right)+\cdots+\beta_{k} d\left(y_{n-1}, y_{n}\right)+\beta_{k+1} d\left(y_{n}, y_{n+1}\right) \\
& +\beta_{1} d\left(y_{n-1}, y_{n}\right)+\cdots+\beta_{k-1} d\left(y_{n-1}, y_{n}\right)+\beta_{k} d\left(y_{n}, y_{n+1}\right) \\
& +\beta_{k+1} d\left(y_{n}, y_{n+1}\right)+\cdots \\
& +\beta_{1} d\left(y_{n-1}, y_{n}\right)+\beta_{2} d\left(y_{n}, y_{n+1}\right)+\cdots+\beta_{k+1} d\left(y_{n}, y_{n+1}\right) .
\end{aligned}
$$


Setting $d_{n}=d\left(y_{n}, y_{n+1}\right)$, we obtain

$$
\begin{aligned}
d_{n} \leq & {\left[\sum_{i=1}^{k} \alpha_{i}\right] d_{n-1}+\left[k \beta_{1}+(k-1) \beta_{2}+\cdots+2 \beta_{k-1}+\beta_{k}\right] d_{n-1} } \\
& +\left[k \beta_{k+1}+(k-1) \beta_{k}+\cdots+2 \beta_{3}+\beta_{2}\right] d_{n}, \\
d_{n} \leq & {\left[\sum_{i=1}^{k} \alpha_{i}+\sum_{i=1}^{k}(k+1-i) \beta_{i}\right] d_{n-1}+\left[\sum_{i=2}^{k+1}(i-1) \beta_{i}\right] d_{n}, } \\
d_{n} \leq & \frac{\sum_{i=1}^{k} \alpha_{i}+\sum_{i=1}^{k+1}(k+1-i) \beta_{i}}{1-\sum_{i=1}^{k+1}(i-1) \beta_{i}} d_{n-1}, \\
d_{n} \leq & \lambda d_{n-1} \text { (say). }
\end{aligned}
$$

Let $A=\sum_{i=1}^{k} \alpha_{i}, B=k \sum_{i=1}^{k+1} \beta_{i}, C=\sum_{i=1}^{k+1}(i-1) \beta_{i}$, then in view of (9) we have $A+B<1$. Therefore

$$
\lambda=\frac{\sum_{i=1}^{k} \alpha_{i}+\sum_{i=1}^{k+1}(k+1-i) \beta_{i}}{1-\sum_{i=1}^{k+1}(i-1) \beta_{i}}=\frac{A+B-C}{1-C}<1 .
$$

By repeating this process, we obtain

$$
d_{n} \leq \lambda^{n} d_{0}
$$

Let $m, n \in \mathbb{N}$ and $m>n$, then it follows from (10) that

$$
\begin{aligned}
d\left(y_{n}, y_{m}\right) & \leq d\left(y_{n}, y_{n+1}\right)+d\left(y_{n+1}, y_{n+2}\right)+d\left(y_{n+2}, y_{n+3}\right)+\cdots+d\left(y_{m-1}, y_{m}\right) \\
& \leq d_{n}+d_{n+1}+d_{n+2}+\cdots \\
& \leq \lambda^{n} d_{0}+\lambda^{n+1} d_{0}+\lambda^{n+2} d_{0}+\cdots \\
& =\left[1+\lambda+\lambda^{2}+\cdots\right] \lambda^{n} d_{0}, \\
d\left(y_{n}, y_{m}\right) & \leq \frac{\lambda^{n}}{1-\lambda} d_{0} .
\end{aligned}
$$

As $\lambda<1$, we have $\frac{\lambda^{n}}{1-\lambda} d_{0} \rightarrow 0$ as $n \rightarrow \infty$. Therefore, it follows from the above inequality that $\lim _{n, m \rightarrow \infty} d\left(y_{n}, y_{m}\right)=0$. Therefore $\left\{y_{n}\right\}=\left\{g x_{n}\right\}$ is a Cauchy sequence. As $g(X)$ is closed, there exist $v \in g(X), u \in X$ such that

$$
\lim _{n \rightarrow \infty} y_{n}=\lim _{n \rightarrow \infty} g x_{n}=g u=v
$$

We shall show that $v$ is a point of coincidence of $f$ and $g$. For any $n \in \mathbb{N}$, we obtain

$$
\begin{aligned}
d(g u, f(u, \ldots, u)) \leq & d\left(g u, y_{n+1}\right)+d\left(y_{n+1}, f(u, \ldots, u)\right) \\
\leq & d\left(g u, y_{n+1}\right)+d\left(f\left(x_{n}, \ldots, x_{n}\right), f(u, \ldots, u)\right) \\
\leq & d\left(g u, y_{n+1}\right)+d\left(f\left(x_{n}, \ldots, x_{n}\right), f\left(x_{n}, \ldots, x_{n}, u\right)\right) \\
& +d\left(f\left(x_{n}, \ldots, x_{n}, u\right), f\left(x_{n}, \ldots, x_{n}, u, u\right)\right)+\ldots \\
& +d\left(f\left(x_{n}, u, \ldots, u\right), f(u, \ldots, u)\right) .
\end{aligned}
$$


By (III) we have $g x_{n} \preceq g u$ for all $n \in \mathbb{N}$, also, as $y_{n}=g x_{n}=f\left(x_{n}, \ldots, x_{n}\right), d_{n}=d\left(g x_{n}, g x_{n+1}\right)$ and $g u=v$. Therefore, using (8) in the above inequality, we obtain

$$
\begin{aligned}
d(v, f(u, \ldots, u)) \leq & \alpha_{k} d\left(y_{n}, v\right)+\beta_{1} d_{n}+\beta_{2} d_{n}+\cdots+\beta_{k} d_{n} \\
& +\beta_{k+1} d(v, f(u, \ldots, u)) \\
& +\alpha_{k-1} d\left(y_{n}, v\right)+\beta_{1} d_{n}+\beta_{2} d_{n}+\cdots \\
& +\beta_{k-1} d_{n}+\beta_{k} d(v, f(u, \ldots, u))+\beta_{k+1} d(v, f(u, \ldots, u)) \\
& +\ldots \\
& +\alpha_{1} d\left(y_{n}, v\right)+\beta_{1} d_{n}+\beta_{2} d(v, f(u, \ldots, u))+\ldots \\
& +\beta_{k+1} d(v, f(u, \ldots, u))+d\left(v, y_{n+1}\right) \\
= & {\left[\sum_{i=1}^{k} \alpha_{i}\right] d\left(y_{n}, v\right)+\left[\sum_{i=1}^{k}(k+1-i) \beta_{i}\right] d_{n} } \\
& +\left[\sum_{i=2}^{k+1}(i-1) \beta_{i}\right] d(v, f(u, \ldots, u))+d\left(v, y_{n+1}\right)
\end{aligned}
$$

that is,

$$
\begin{aligned}
& (1-C) d(v, f(u, \ldots, u)) \leq A d\left(y_{n}, v\right)+(B-C) d\left(y_{n}, y_{n+1}\right)+d\left(v, y_{n+1}\right), \\
& (1-C) d(v, f(u, \ldots, u)) \leq(A+B-C) d\left(y_{n}, v\right)+(1+B-C) d\left(y_{n+1}, v\right) .
\end{aligned}
$$

As $\lim _{n \rightarrow \infty} d\left(y_{n}, v\right)=0$ and $1-C=1-\sum_{i=1}^{k+1}(i-1) \beta_{i}>0$, therefore it follows from the above inequality that

$$
d(v, f(u, \ldots, u))=0, \quad \text { that is, } \quad f(u, \ldots, u)=v=g u .
$$

Thus, $u$ is a coincidence point and $v$ is a corresponding point of coincidence of $f$ and $g$. Suppose, $f$ and $g$ are weakly compatible, then by (11) we have

$$
f(v, \ldots, v)=f(g u, \ldots, g u)=g(f(u, \ldots, u))=g v .
$$

Again, by (III), $g u \preceq g g u=g v$; therefore using (8) and a similar process as several times before, we obtain

$$
\begin{aligned}
d(v, f(v, \ldots, v))= & d(f(u, \ldots, u), f(v, \ldots, v)) \\
\leq & d(f(u, \ldots, u), f(u, \ldots, u, v)) \\
& +d(f(u, \ldots, u, v), f(u, \ldots, u, v, v))+\ldots \\
& +d(f(u, v, \ldots, v), f(v, \ldots, v)) \\
\leq & A d(g u, g v)+(B-C) d(g u, f(u, \ldots, u)) \\
& +C d(g v, f(v, \ldots, v)) \\
= & A d(v, f(v, \ldots, v)) .
\end{aligned}
$$


As $A=\sum_{i=1}^{k} \alpha_{i}<1$, we obtain

$$
d(v, f(v, \ldots, v))=0, \quad \text { that is, } f(v, \ldots, v)=v=g v .
$$

Thus $v$ is a common fixed point of $f$ and $g$. Suppose that the set of common fixed points is $g$-well ordered. We shall show that the common fixed point is unique. Assume on the contrary that $v_{0}$ is another common fixed point of $f$ and $g$, that is, $v_{0}=f\left(v_{0}, \ldots, v_{0}\right)=g v_{0}$ and $v \neq v_{0}$. As $v$ and $v_{0}$ are $g$-comparable, let for example $g v \preceq g v_{0}$. From (8), it follows that

$$
\begin{aligned}
d\left(v, v_{0}\right)= & d\left(f(v, \ldots, v), f\left(v_{0}, \ldots, v_{0}\right)\right) \\
\leq & d\left(f(v, \ldots, v), f\left(v, \ldots, v, v_{0}\right)\right) \\
& +d\left(f\left(v, \ldots, v, v_{0}\right), f\left(v, \ldots, v, v_{0}, v_{0}\right)\right)+\ldots \\
& +d\left(f\left(v, v_{0}, \ldots, v_{0}\right), f\left(v_{0}, \ldots, v_{0}\right)\right) \\
\leq & A d\left(g v, g v_{0}\right)+(B-C) d(g v, f(v, \ldots, v))+C d\left(g v_{0}, f\left(v_{0}, \ldots, v_{0}\right)\right) \\
= & A d\left(v, v_{0}\right) .
\end{aligned}
$$

As $A=\sum_{i=1}^{k} \alpha_{i}<1$, we obtain $d\left(v, v_{0}\right)=0$, that is, $v=v_{0}$, a contradiction. Therefore the common fixed point is unique. For converse, if a common fixed point of $f$ and $g$ is unique, then the set of common fixed points of $f$ and $g$ is singleton, and thus $g$-well ordered.

Remark 2.2 Let $(X, \preceq, d)$ be an ordered metric space, and let $f, g: X \rightarrow X$ be two mappings. Then $f$ is called an ordered $g$-weak contraction if

$$
d(f x, f y) \leq \alpha_{1} d(g x, g y)+\alpha_{2} d(f x, g x)+\alpha_{3} d(f y, g y)
$$

for all $x, y \in X$ with $x \preceq y$, where $\alpha_{1}, \alpha_{2}, \alpha_{3}$ are nonnegative constants such that $\alpha_{1}+\alpha_{2}+$ $\alpha_{3}<1$. If the above inequality is satisfied for all $x, y \in X$, then $f$ is called a $g$-weak contraction (see [35]). For $k=1$ in Theorem 2.1, we get a fixed point result for an ordered $g$-weak contraction in metric spaces.

The following is a fixed point result for ordered Prešić-Reich type mappings in metric spaces and can be obtained by taking $g=I_{X}$ (that is, the identity mapping of $X$ ) in Theorem 2.1 .

Corollary 2.3 Let $(X, \preceq, d)$ be an ordered complete metric space. Let $k$ be a positive integer, $f: X^{k} \rightarrow X$ be a mapping such that the following conditions hold:

(I) $f$ is an ordered Prešić-Reich type contraction;

(II) there exists $x_{0} \in X$ such that $x_{0} \preceq f\left(x_{0}, x_{0}, \ldots, x_{0}\right)$;

(III) $f$ is nondecreasing (with respect to ' $\preceq$ ');

(IV) if a nondecreasing sequence $\left\{x_{n}\right\}$ converges to $u \in X$, then $x_{n} \preceq u$ for all $n \in \mathbb{N}$.

Then $f$ has a fixed point. Moreover, the set of fixed points off is well ordered if and only if $f$ has a unique fixed point.

The following corollary is a generalization of the result of Prešic in an ordered metric space and can be obtained by taking $\beta_{i}=0$ for $1 \leq i \leq k+1$ in Theorem 2.1. 
Corollary 2.4 Let $(X, \preceq, d)$ be an ordered complete metric space. Let $k$ be a positive integer, $f: X^{k} \rightarrow X$ and $g: X \rightarrow X$ be two mappings such that $f\left(X^{k}\right) \subset g(x), g(X)$ is a closed subset of $X$ and

$$
d\left(f\left(x_{1}, x_{2}, \ldots, x_{k}\right), f\left(x_{2}, x_{3}, \ldots, x_{k+1}\right)\right) \leq \sum_{i=1}^{k} \alpha_{i} d\left(g x_{i}, g x_{i+1}\right)
$$

for all $x_{1}, x_{2}, \ldots, x_{k+1} \in X$ with $g x_{1} \preceq g x_{2} \preceq \cdots \preceq g x_{k+1}$, where $\alpha_{i}$ are nonnegative constants such that $\sum_{i=1}^{k} \alpha_{i}<1$. Suppose that the following conditions hold:

(I) there exists $x_{0} \in X$ such that $g x_{0} \preceq f\left(x_{0}, x_{0}, \ldots, x_{0}\right)$;

(II) $f$ is $g$-nondecreasing;

(III) if a nondecreasing sequence $\left\{g x_{n}\right\}$ converges to $g u \in X$, then $g x_{n} \preceq$ gu for all $n \in \mathbb{N}$ and $g u \preceq g g u$.

Then $f$ and $g$ have a point of coincidence. If, in addition, $f$ and $g$ are weakly compatible, then $f$ and $g$ have a common fixed point $v \in X$. Moreover, the set of common fixed points of $f$ and $g$ is $g$-well ordered if and only iff and $g$ have a unique common fixed point.

The following corollary generalizes the result of Păcurar [10] in ordered metric spaces and can be obtained by taking $\alpha_{i}=0$ for $1 \leq i \leq k$ in Theorem 2.1.

Corollary 2.5 Let $(X, \preceq, d)$ be an ordered complete metric space. Let $k$ be a positive integer, $f: X^{k} \rightarrow X$ and $g: X \rightarrow X$ be two mappings such that $f\left(X^{k}\right) \subset g(X), g(X)$ is a closed subset of $X$ and

$$
d\left(f\left(x_{1}, x_{2}, \ldots, x_{k}\right), f\left(x_{2}, x_{3}, \ldots, x_{k+1}\right)\right) \leq \sum_{i=1}^{k+1} \beta_{i} d\left(g x_{i}, f\left(x_{i}, x_{i}, \ldots, x_{i}\right)\right)
$$

for all $x_{1}, x_{2}, \ldots, x_{k+1} \in X$ with $g x_{1} \preceq g x_{2} \preceq \cdots \preceq g x_{k+1}$, where $\beta_{i}$ are nonnegative constants such that $k \sum_{i=1}^{k+1} \beta_{i}<1$. Suppose that the following conditions hold:

(I) there exists $x_{0} \in X$ such that $g x_{0} \preceq f\left(x_{0}, x_{0}, \ldots, x_{0}\right)$;

(II) $f$ is $g$-nondecreasing;

(III) if a nondecreasing sequence $\left\{g x_{n}\right\}$ converges to gu $\in X$, then $g x_{n} \preceq$ gu for all $n \in \mathbb{N}$ and $g u \preceq g g u$.

Then $f$ and $g$ have a point of coincidence. If, in addition, $f$ and $g$ are weakly compatible, then $f$ and $g$ have a common fixed point $v \in X$. Moreover, the set of common fixed points of $f$ and $g$ is $g$-well ordered if and only if $f$ and $g$ have a unique common fixed point.

The following example illustrates that an ordered Prešić-Reich type contraction may not be an ordered Prešić type or ordered Prešić-Kannan type or Prešić-Reich type contraction; moreover, that the fixed point of an ordered Prešić-Reich type contraction may not be unique (when the set of fixed points of $f$ is not well-ordered).

Example 2.6 Let $X=[0,2]$ and order relation ' $\preceq$ ' be defined by

$$
\preceq=\{(x, y): x, y \in[0,1] \text { with } y \leq x\} \cup\{(x, y): x, y \in(1,2) \text { with } y \leq x\} \cup\{(2,2)\}
$$


and let $d$ be the usual metric on $X$. Then $(X, \preceq, d)$ is an ordered complete metric space. For $k=2$, define $f: X^{2} \rightarrow X$ by

$$
f(x, y)= \begin{cases}\frac{1}{12} & \text { if } x=y=1, \\ 2 & \text { if } x=y=2, \\ \frac{x+y}{2}-1 & \text { if }(x, y) \in[0,1) \times\{2\} \cup\{2\} \times[0,1), \\ \frac{x+y}{6} & \text { otherwise. }\end{cases}
$$

Then:

(a) $f$ is not an ordered Prešić type contraction;

(b) $f$ is not an ordered Prešić-Kannan type contraction;

(c) $f$ is not a Prešić-Reich type contraction;

(d) $f$ is an ordered Prešić-Reich type contraction with $\alpha_{1}=\alpha_{2}=\frac{1}{6}, \beta_{1}=\beta_{2}=\beta_{3}=\frac{1}{10}$.

Proof (a) For $k=2$, (5) becomes

$$
d\left(f\left(x_{1}, x_{2}\right), f\left(x_{2}, x_{3}\right)\right) \leq \alpha_{1} d\left(x_{1}, x_{2}\right)+\alpha_{2} d\left(x_{2}, x_{3}\right)
$$

for all $x_{1}, x_{2}, x_{3} \in X$ with $x_{1} \preceq x_{2} \preceq x_{3}$, where $\alpha_{1}, \alpha_{2}$ are nonnegative constants such that $\alpha_{1}+\alpha_{2}<1$. Note that $1 \preceq 1 \preceq \frac{9}{10}$, therefore for $x_{1}=x_{2}=1, x_{3}=\frac{9}{10}$, (14) becomes

$$
\begin{aligned}
& d\left(f(1,1), f\left(1, \frac{9}{10}\right)\right) \leq \alpha_{1} d(1,1)+\alpha_{2} d\left(1, \frac{9}{10}\right), \\
& d\left(\frac{1}{12}, \frac{19}{60}\right) \leq \alpha_{2} \frac{1}{10}, \\
& \frac{7}{3} \leq \alpha_{2} .
\end{aligned}
$$

But $\alpha_{1}+\alpha_{2}<1$ and therefore the above inequality will never hold. Thus $f$ is not an ordered Prešić type contraction.

(b) For $k=2$, (6) becomes

$$
\begin{gathered}
d\left(f\left(x_{1}, x_{2}\right), f\left(x_{2}, x_{3}\right)\right) \leq \beta\left[d\left(x_{1}, f\left(x_{1}, x_{1}\right)\right)+d\left(x_{2}, f\left(x_{2}, x_{2}\right)\right)\right. \\
\left.+d\left(x_{3}, f\left(x_{3}, x_{3}\right)\right)\right]
\end{gathered}
$$

for all $x_{1}, x_{2}, x_{3} \in X$ with $x_{1} \preceq x_{2} \preceq x_{3}$, where $\beta$ is a nonnegative constant such that $\beta<\frac{1}{6}$. Note that $x \preceq 0 \preceq 0$ for all $x \in(0,1)$ and therefore for $x_{2}=x_{3}=0, x_{1}=x \in(0,1)$, (15) becomes

$$
\begin{aligned}
& d(f(x, 0), f(0,0)) \leq \beta_{1} d(x, f(x, x))+\beta_{2} d(0, f(0,0))+\beta_{3} d(0, f(0,0)), \\
& d\left(\frac{x}{6}, 0\right) \leq \beta_{1} d\left(x, \frac{x}{3}\right)+\beta_{2} d(0,0)+\beta_{3} d(0,0), \\
& \frac{x}{6} \leq \beta_{1} \frac{2 x}{3} .
\end{aligned}
$$

But $\beta<\frac{1}{6}$, and therefore the above inequality will never hold. Thus $f$ is not an ordered Prešić-Kannan type contraction. 
(c) For $k=2$, (7) becomes

$$
\begin{aligned}
d\left(f\left(x_{1}, x_{2}\right), f\left(x_{2}, x_{3}\right)\right) \leq & \alpha_{1} d\left(x_{1}, x_{2}\right)+\alpha_{2} d\left(x_{2}, x_{3}\right) \\
& +\beta_{1} d\left(x_{1}, f\left(x_{1}, x_{1}\right)\right) \\
& +\beta_{2} d\left(x_{2}, f\left(x_{2}, x_{2}\right)\right)+\beta_{3} d\left(x_{3}, f\left(x_{3}, x_{3}\right)\right),
\end{aligned}
$$

where $\alpha_{1}, \alpha_{2}, \beta_{1}, \beta_{2}, \beta_{3}$ are nonnegative constants such that $\sum_{i=1}^{2} \alpha_{i}+2 \sum_{i=1}^{3} \beta_{i}<1$. If $f$ is a Prešić-Reich type contraction, then inequality (16) must be satisfied for all $x_{1}, x_{2}, x_{3} \in X$. Note that for $x_{1}=x_{2}=2, x_{3}=0$, (16) becomes

$$
\begin{aligned}
& d(f(2,2), f(2,0)) \leq \alpha_{1} d(2,2)+\alpha_{2} d(2,0) \\
& +\beta_{1} d(2, f(2,2))+\beta_{2} d(2, f(2,2))+\beta_{3} d(0, f(0,0)), \\
& d(2,0) \leq \alpha_{2} d(2,0)+\beta_{1} d(2,2)+\beta_{2} d(2,2)+\beta_{3} d(0,0), \\
& 2 \leq 2 \alpha_{2} \text {. }
\end{aligned}
$$

But $\sum_{i=1}^{2} \alpha_{i}+2 \sum_{i=1}^{3} \beta_{i}<1$, and therefore the above inequality will never hold. Thus $f$ is not a Prešić-Reich type contraction.

(d) If $f$ is an ordered Prešić-Reich type contraction, then inequality (16) must be satisfied for all $x_{1}, x_{2}, x_{3} \in X$ with $x_{1} \preceq x_{2} \preceq x_{3}$. Indeed, we have to check the validity of (16) only for $x_{1}, x_{2}, x_{3} \in[0,1], x_{1}, x_{2}, x_{3} \in(1,2)$ and $x_{1}=x_{2}=x_{3}=2$. If $x_{1}=x_{2}=x_{3}=1$ or $x_{1}=x_{2}=x_{3}=2$, then (16) is satisfied trivially. If $x_{1}, x_{2}, x_{3} \in[0,1)$ or $x_{1}, x_{2}, x_{3} \in(1,2)$ with $x_{1} \preceq x_{2} \preceq x_{3}$, that is, $x_{3} \leq x_{2} \leq x_{1}$, then (16) becomes

$$
\begin{aligned}
& d\left(\frac{x_{1}+x_{2}}{6}, \frac{x_{2}+x_{3}}{6}\right) \leq \alpha_{1} d\left(x_{1}, x_{2}\right)+\alpha_{2} d\left(x_{2}, x_{3}\right) \\
& +\beta_{1} d\left(x_{1}, \frac{x_{1}}{3}\right)+\beta_{2} d\left(x_{2}, \frac{x_{2}}{3}\right)+\beta_{3} d\left(x_{3}, \frac{x_{3}}{3}\right), \\
& \frac{x_{1}-x_{3}}{6} \leq \alpha_{1}\left(x_{1}-x_{2}\right)+\alpha_{2}\left(x_{2}-x_{3}\right)+\frac{2 x_{1}}{3} \beta_{1}+\frac{2 x_{2}}{3} \beta_{2}+\frac{2 x_{3}}{3} \beta_{3},
\end{aligned}
$$

which is valid for $\alpha_{1}=\alpha_{2}=\frac{1}{6}, \beta_{1}=\beta_{2}=\beta_{3}=\frac{1}{10}$. If any one of $x_{1}, x_{2}, x_{3}$ is equal to 1 , then with a similar process one can verify the same result. If any two of $x_{1}, x_{2}, x_{3}$ are equal to 1 , for example, let $x_{1}=x_{2}=1, x_{3} \in[0,1)$, then (16) becomes

$$
\begin{aligned}
& d\left(\frac{1}{12}, \frac{1+x_{3}}{6}\right) \leq \alpha_{1} d(1,1)+\alpha_{2} d\left(1, x_{3}\right) \\
&+\beta_{1} d\left(1, \frac{1}{12}\right)+\beta_{2} d\left(1, \frac{1}{12}\right)+\beta_{3} d\left(x_{3}, \frac{x_{3}}{3}\right), \\
& \frac{1+2 x_{3}}{12} \leq \alpha_{2}\left(1-x_{3}\right)+\frac{11}{12} \beta_{1}+\frac{11}{12} \beta_{2}+\frac{2 x_{3}}{3} \beta_{3},
\end{aligned}
$$

which is valid for $\alpha_{1}=\alpha_{2}=\frac{1}{6}, \beta_{1}=\beta_{2}=\beta_{3}=\frac{1}{10}$. Similarly, in all possible cases, (16) is satisfied for $\alpha_{1}=\alpha_{2}=\frac{1}{6}, \beta_{1}=\beta_{2}=\beta_{3}=\frac{1}{10}$. Thus, $f$ is an ordered Prešić-Reich type contraction. All the conditions of Corollary 2.3 (except the set of fixed points of $f$ is well ordered) are satisfied and the set of fixed points of $f$ is $\mathcal{F}=\{0,2\}$. Note that the set of fixed points of $f$, that is $\mathcal{F}$, is not well ordered (as $(0,2),(2,0) \notin \preceq)$ and fixed point $f$ is not unique. 


\section{Competing interests}

All authors of the present paper disclose no actual potential conflict of interests including any financial, personal or other relationships with people or organizations.

\section{Authors' contributions}

All authors contributed equally and significantly in writing this paper. All authors read and approved the final manuscript.

\section{Author details}

'Department of Applied Mathematics, Shri Vaishnav Institute of Technology and Science, Gram Baroli, Sanwer Road, Indore, M.P. 453331, India. ²Department of Mathematics, Faculty of Mechanical Engineering, University of Belgrade, Kraljice Marije 16, Belgrade, 11120, Serbia. ${ }^{3}$ Department of Industrial Engineering, Faculty of Mechanical Engineering, University of Belgrade, Kraljice Marije 16, Belgrade, 11120, Serbia.

\section{Acknowledgements}

This paper is supported by Grant No. 1740024 from the Ministry of Science and Technical Development of the Republic of Serbia.

\section{Received: 17 June 2013 Accepted: 24 September 2013 Published: 09 Nov 2013}

\section{References}

1. Kannan, R: Some results on fixed points. Bull. Calcutta Math. Soc. 60, 71-76 (1968)

2. Kannan, R: Some results on fixed points. II. Am. Math. Mon. 76, 405-408 (1969)

3. Reich, S: Some remarks concerning contraction mappings. Can. Math. Bull. 14, 121-124 (1971)

4. Prešić, S: Sur la convergence des suites. C. R. Acad. Sci. Paris 260, 3828-3830 (1965)

5. Prešić, S: Sur une classe d'inéquations aux différences finite et sur la convergence de certaines suites. Publ. Inst. Math. (Belgr.) 5(19), 75-78 (1965)

6. Shukla, S, Radenović, S: A generalization of Prešić type mappings in 0-complete ordered partial metric spaces. Chin. J. Math. 2013, Article ID 859531 (2013). doi:10.1155/2013/859531

7. Shukla, S: Prešić type results in 2-Banach spaces. Afr. Math. (2013). doi:10.1007/s13370-013-0174-2

8. Ćirić, LB, Prešić, S: On Prešić type generalisation of Banach contraction principle. Acta Math. Univ. Comen. LXXVI(2), 143-147 (2007)

9. Păcurar, M: A multi-step iterative method for approximating common fixed points of Prešić-Rus type operators on metric spaces. Stud. Univ. Babeş-Bolyai, Math. LV(1), 416-420 (2010)

10. Pǎcurar, M: Approximating common fixed points of Prešić-Kannan type operators by a multi-step iterative method. An. Şt. Univ. Ovidius Constanţa 17(1), 153-168 (2009)

11. Pǎcurar, M: Common fixed points for almost Prešić type operators. Carpath. J. Math. 28(1), 117-126 (2012)

12. Khan, M, Berzig, M, Samet, B: Some convergence results for iterative sequences of Prešić type and applications. Adv. Differ. Equ. (2012). doi:10.1186/1687-1847-2012-38

13. George, R, Reshma, K, Rajagopalan, R: A generalised fixed point theorem of Prešić type in cone metric spaces and application to Markov process. Fixed Point Theory Appl. (2011). doi:10.1186/1687-1812-2011-85

14. Shukla, S, Fisher, B: A generalization of Prešić type mappings in metric-like spaces. J. Oper. 2013, Article ID 368501 (2013). doi:10.1155/2013/368501

15. Shukla, S, Sen, R, Radenović, S: Set-valued Prešić type contraction in metric spaces. An. Ştiinţ. Univ. Al. I. Cuza laşi. Mat. (in press)

16. Shukla, S, Sen, R: Set-valued Prešić-Reich type mappings in metric spaces. Rev. R. Acad. Cienc. Exactas Fís. Nat., Ser. A Mat. (2012). doi:10.1007/s13398-012-0114-2

17. Shukla, S, Radenović, S, Pantelić, S: Some fixed point theorems for Prešić-Hardy-Rogers type contractions in metric spaces. J. Math. 2013, Article ID 295093 (2013). doi:10.1155/2013/295093

18. Malhotra, S, Shukla, S, Sen, R: A generalization of Banach contraction principle in ordered cone metric spaces. J. Adv. Math. Stud. 5(2), 59-67 (2012)

19. Chen, Y: A Prešić type contractive condition and its applications. Nonlinear Anal. (2009). doi:10.1016/j.na.2009.03.006

20. Ran, ACM, Reurings, MCB: A fixed point theorem in partially ordered sets and some application to matrix equations. Proc. Am. Math. Soc. 132, 1435-1443 (2004)

21. Nieto, J, Lopez, R: Contractive mapping theorems in partially ordered sets and applications to ordinary differential equations. Order 22, 223-239 (2005)

22. Nieto, J, Lopez, R: Existence and uniqueness of fixed point in partially ordered sets and applications to ordinary differential equations. Acta Math. Sin. Engl. Ser. 23(12), 2205-2212 (2007)

23. Paesano, D, Vetro, P: Suzuki's type characterizations of completeness for partial metric spaces and fixed points for partially ordered metric spaces. Topol. Appl. 159, 911-920 (2012)

24. Vetro, F, Radenović, S: Nonlinear $\psi$-quasi-contractions of Ćirić-type in partial metric spaces. J. Nonlinear Anal. Optim. Theory Appl. 219, 1594-1600 (2012)

25. Aydi, H: Fixed point results for weakly contractive mappings in ordered partial metric spaces. J. Adv. Math. Stud. 4(2), 1-12(2011)

26. Aydi, H: Fixed point theorems for generalized weakly contractive condition in ordered partial metric spaces. J. Nonlinear Anal. Optim., Theory Appl. 2(2), 33-48 (2011)

27. Aydi, H: Some coupled fixed point results on partial metric spaces. Int. J. Math. Math. Sci. 2011, Article ID 647091 (2011)

28. Aydi, H: Some fixed point results in ordered partial metric spaces. J. Nonlinear Sci. Appl. 4(3), 210-217 (2011)

29. Nashine, H, Kadelburg, Z, Radenović, S, Kim, J: Fixed point theorems under Hardy-Rogers contractive conditions on 0-complete ordered partial metric spaces. Fixed Point Theory Appl. 2012, 180 (2012)

30. Altun, I, Erduran, A: Fixed point theorems for monotone mappings on partial metric spaces. Fixed Point Theory Appl. 2011, Article ID 508730 (2011) 
31. Radenović, S, Kadelburg, Z: Generalized weak contractions in partially ordered metric spaces. Comput. Math. Appl. 60, 1776-1783 (2010). doi:10.1016/j.camwa.2010.07.008

32. Shatanawi, W, Samet, B, Abbas, M: Coupled fixed point theorems for mixed monotone mappings in ordered partial metric spaces. Math. Comput. Model. 55, 680-687 (2012)

33. Luong, N, Thuan, N: Some fixed point theorems of Prešić-Ćirić type. Acta Univ. Apulensis 30, 237-249 (2012)

34. Abbas, $\mathrm{M}$, Jungck, J: Common fixed point results for noncommuting mappings without continuity in cone metric spaces. J. Math. Anal. Appl. 341, 416-420 (2008)

35. Vetro, P: Common fixed points in cone metric spaces. Rend. Circ. Mat. Palermo 56(2), 464-468 (2007)

10.1186/1029-242X-2013-520

Cite this article as: Shukla et al.: Some coincidence and common fixed point theorems for ordered Prešić-Reich type contractions. Journal of Inequalities and Applications 2013, 2013:520

Submit your manuscript to a SpringerOpen ${ }^{\odot}$ journal and benefit from:

- Convenient online submission

- Rigorous peer review

- Immediate publication on acceptance

- Open access: articles freely available online

- High visibility within the field

- Retaining the copyright to your article

Submit your next manuscript at $\boldsymbol{s p r i n g e r o p e n . c o m ~}$ 